\title{
LOSS RULES OF TOTAL NITROGEN AND TOTAL PHOSPHORUS IN THE SOILS OF SOUTHWEST MOUNTAINS IN HENAN PROVINCE, CHINA UNDER ARTIFICIAL RAINFALL
}

\author{
WANG, G. ${ }^{*}-\mathrm{LI}, \mathrm{Z}^{2}{ }^{2}-$ ZHANG, ${ }^{3}{ }^{3}-\mathrm{LU}, \mathrm{Y}^{2}{ }^{2}-\mathrm{CHEN}, \mathrm{Z} .{ }^{4}$ \\ ${ }^{1}$ Hydrology and Water Resources of Yellow River Scientific Research Institute \\ Zhengzhou, China \\ ${ }^{2}$ Hydrology and Water Resources Bureau in Henan Province, Zhengzhou, China \\ ${ }^{3}$ Yellow River Henan Bureau, Zhengzhou, China \\ ${ }^{4}$ Hydrology and Water Resources Survey Bureau of Nanyang in Henan Province \\ Nanyang, China \\ *Corresponding author \\ e-mail: zhonggw2020@163.com
}

(Received 27 $7^{\text {th }}$ Sep 2018; accepted $28^{\text {th }}$ Nov 2018)

\begin{abstract}
To seek a feasible land use structure to control non-point pollution, by indoor artificial rainfall test, total nitrogen (TN) and total phosphorus (TP) as nutrient indexes, five types of soil in southwest of Henan Province were selected to study the nutrient loss rules under six kinds of rainfall intensity. The results were that: (1) the nutrient loss, runoff and sediment yield were accordingly increased with the increase of rainfall intensity in same type of soil. On same rainfall intensity, nutrient loss in the soil of farmland was larger than that in woodland and grassland, the nutrient content in terrace was higher than that in other soil. (2) The nutrient content in silt load was higher than that in bed load out of nutrient enrichment in sediment drain. There was a relationship of power index between nutrient loss and runoff while there was a linear correlation for sediment yield and nutrient loss. (3) The nutrients in farmland mainly went away with sediment erosion while in forest land, TN mainly drained with runoff and TP eroded with sediment. (4) At 0.01 of confidence level, the effect of rainfall intensity on nutrient loss was significant in runoff and sediment; land use types became more significant to TN loss than to TP drain in runoff while it had no prominent effect on the nutrient drain with sediment. Conclusion: It is important to popularize the projects of slope to terrace and grain for green in the region to improve crop yield and reduce non-point source pollution.
\end{abstract}

Keywords: artificial rainfall, rainfall intensity, land use type, soil erosion, runoff, nutrients loss

\section{Introduction}

Water pollution is an international problem and agricultural non-point source pollution is its main pollution form ( $\mathrm{Li}$ and Chen, 2015). The survey showed the nonpoint source pollution accounted for about two-thirds of total pollution load in the United States and $68 \%$ to $83 \%$ of which was agricultural non-point source pollution (Li and $\mathrm{Hu}, 2013)$. The research found that agricultural non-point source pollution was a major cause of eutrophication of water environment in Denmark (Beibei at al., 2017). The emissions of agricultural non-point pollutant have exceeded the source of industry and life and became the first pollution source inland (Yang et al., 2013). As an important form of non-point source pollution and carrier of transportation, soil erosion is root reason for bringing water bodies pollution, such as lakes, reservoirs, rivers and so on $(\mathrm{Li}, 2013)$. The water pollution which is caused by soil erosion had caused economic losses between 2.2 to 7 billion dollars in the USA (Zhou, 2014). Nitrogen and 
phosphorus of soil are either the nutrients required by crops or important source of agricultural non-point pollution (Yu et al., 2013). Artificial rainfall method is a common way to study soil erosion in small scale land use manner which not only can test the research results of natural rainfall, but also can make up for the results that cannot be obtained via the natural rainfall in short duration (Wang et al., 2017b; Xi et al., 2014; He et al., 2014).

Danjiangkou Reservoir is water source area of the south-to-north water diversion middle route project, whose water quality is directly related to the stand or fall of the project (Zhang et al., 2018). Soil erosion is serious in upstream of the reservoir due to topography, soil, vegetation, rainfall and human activities, which will lead to regional non-point pollutants boiling up and scope expands unceasingly without control measures, such as chemical fertilizers and pesticides residue, directly affecting water quality of the reservoir (Wang et al., 2017c; Zhang et al., 2015). The research is less on nutrient loss of different land use types in the region up to date. Indoor artificial rainfall experiments are adopted in the study with familiar land use types selected in southwest mountains of Henan Province to explore the rule of nutrients washing away indifferent soil and various rainfall intensity to probe an economical and practical cultivation structure that will be suitable to local ecological environment and conservation of soil and water.

\section{Materials and methods}

\section{Test materials and conditions}

The experiments were done by slope village and test equipment included five parts: artificial rainfall simulator, trial soil bin, sampling system of runoff and sediment, runoff measurement system and nutrients testing system. Artificial rainfall device was made of steel plate with 2-mm thickness keeping five degrees inclined, total height of which was $1.6 \mathrm{~m}$. The water distributor with uniform pore size was installed above the device and raining height was $1.05 \mathrm{~m}$, rotor flow meter was set up to control rainfall intensity. The soil bin size was $70 \mathrm{~cm}$ in length, $40 \mathrm{~cm}$ in width and $20 \mathrm{~cm}$ in height; runoff exporting size was $30 \mathrm{~cm}$ in length, $3 \mathrm{~cm}$ in width and $3 \mathrm{~cm}$ in height; a basin was placed at the exit of runoff.

The experiments of artificial rainfall had been done during April to August in 2012 in institute of soil and water conservation Chinese Academy of Sciences (CAS) and rainfall intensity was respectively designed as $0.5,1.0,1.5,2.0,2.5$ and $3.0 \mathrm{~mm}^{\bullet} \mathrm{min}^{-1}$. After filling the soil into the soil bin, selecting rainfall intensity and turning on the rainfall simulation device, the time was recorded and the samples of water and soil were collected every $10 \mathrm{~min}$ when the runoff appeared. $500 \mathrm{ml}$ runoffs were taken out from basin when the rain flowed into the basin settled down for $10 \mathrm{~min}$. After filtering and drying the runoff, the weighed value of the soil was the amount of silt load and the rest of soil in basin was bed load which was collected dried and weighed. After $100 \mathrm{~min}$ when the rainfall was stopped and the soil was dug up, another kind of soil was put into the bin to continue the rainfall test in the same rainfall intensity. The tested soil was placed in the container dried naturally and waiting for next rainfall intensity. The nutrients loss of five kinds of soil was tested in sequence under six types of rainfall intensity.

The tested soil was from five land use types in southwest mountains of Henan Province near Danjiangkou Reservoir: timber forest, shrubby grassland, terrace, slope 
cropland and waste-grassland. Firstly, sample plots of the five soil types were selected and then those soil types of plough layer keeping original state were collected respectively and carried back to the laboratory. The amounts of soil filled were calculated by the area of soil bin and bulk weight. The soil was compacted once with $2.5 \mathrm{~cm}$ thickness soil filled and the surface of soil was loosened before filling the upper soil to prevent the soil delaminating.

\section{Test items and method}

The content of total phosphorus (TP) and total nitrogen (TN) need to be tested in the samples of sediment and runoff, tested methods of which are shown in Table 1.

Table 1. The test items and methods

\begin{tabular}{c|c|c|c}
\hline Samples & Indexes & Tested methods & Tested standard \\
\hline \multirow{2}{*}{ Runoff } & TN & $\begin{array}{c}\text { Alkaline potassium persulfate digestion-UV spectro } \\
\text { photometric method }\end{array}$ & GB 11894-89 (Huan, 2012) \\
\cline { 2 - 4 } & TP & Ammonium molybdate spectrophotometric method & $\begin{array}{c}\text { GB11893-89 (Shen and Li, } \\
\text { 2013) }\end{array}$ \\
\hline \multirow{2}{*}{ Sediment } & TN & Semi-micro Kjeldahl method & $\begin{array}{c}\text { GB7173-87 (Mureithi et } \\
\text { al., 2014) }\end{array}$ \\
\cline { 2 - 4 } & TP & Ammonium molybdate spectrophotometric method & $\begin{array}{c}\text { Soil analysis (3 (2d edition) } \\
\text { (Wang et al., 2016) }\end{array}$ \\
\hline
\end{tabular}

\section{Data processing methods}

The software of EXCEL, PSS and SAS were used to analyze and study the experimental data, in order to find out the hidden rules in these data.

\section{Results and discussion}

\section{The nutrients change in the samples of runoff}

In above five kinds of soil, changing rule of TN and TP in runoff was shown in Figure $1 a, b$.

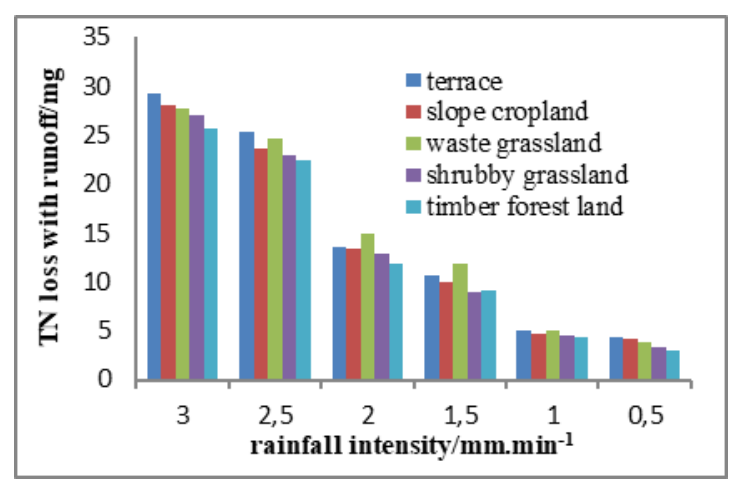

a

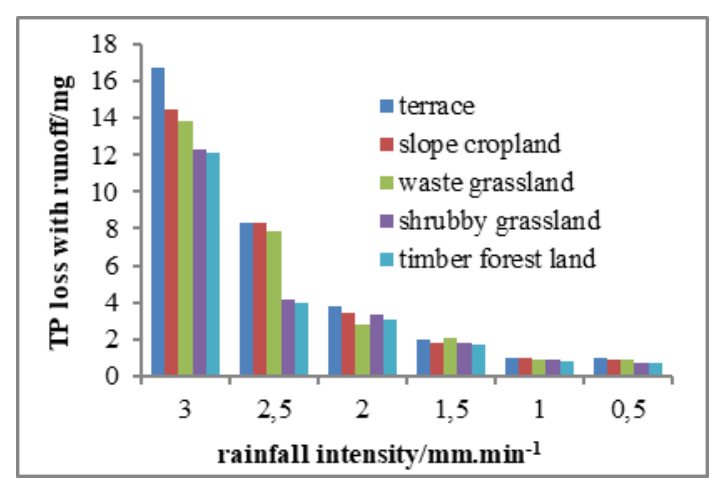

b

Figure 1. The rule of TN erosion (a) and TP drain (b) in runoff samples 
From two figures, the loss of nutrients gradually reduced with runoff decreasing by reduction of rainfall intensity. The larger rainfall intensity was, the more runoff and nutrients loss were in the same type soil. On the whole, nutrients loss in the soils of terrace, hilly land and waste grassland were slightly larger than the one in woodland and shrubby grassland in same rainfall intensity which showed forest land and grassland had a better effect on preventing water and soil losing; the concentration of TP and TN in runoff of terrace was higher than that in other soil, which indicated the engineering of slope to terrace had a very good effect on water conservation.

Farmland (terraces and slope cropland) needed to be ploughed and fertilized when wheat reaped and crop were planted, which caused huge loss of nitrogen and phosphorus on rainfall season especially in the downpour. Large amounts of nitrogen and phosphorus flow into tributaries with runoff and eventually into Danjiangkou Reservoir which seriously threats water quality of the reservoir. The experiments showed the projects of turn hillsides into terrace and returning farmland to forest and grass had important practical significance, which could reduce soil erosion and nonpoint source pollution (Wu et al., 2015).

\section{The nutrients change rule in sediment drain}

By Figure $2 a, b$, the nutrients loss in sediment drain basically decreased with reduction of rainfall intensity in same soil, and the larger rainfall intensity was, the higher sediment yield and nutrients lost. The loss of TN and TP in farmland soil were respectively 36.2 115.98 times and 10.1 81.4 times of forest and grassland in corresponding rainfall intensity because of better soil structure for the latter, which was in accordance with Tang Jie's research (Tang et al., 2012).

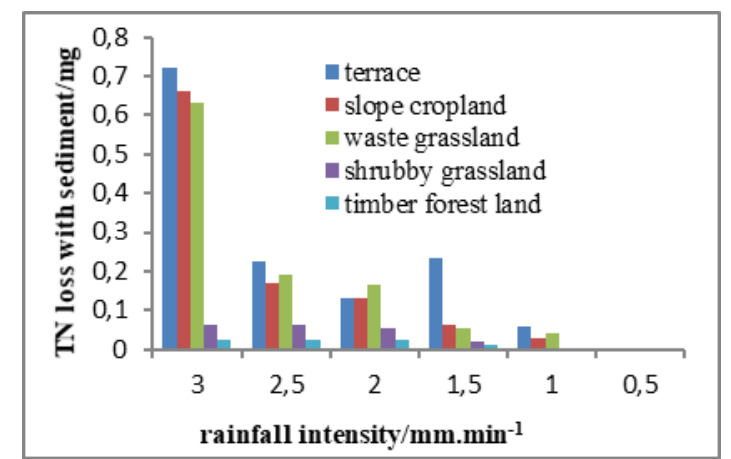

$\mathbf{a}$

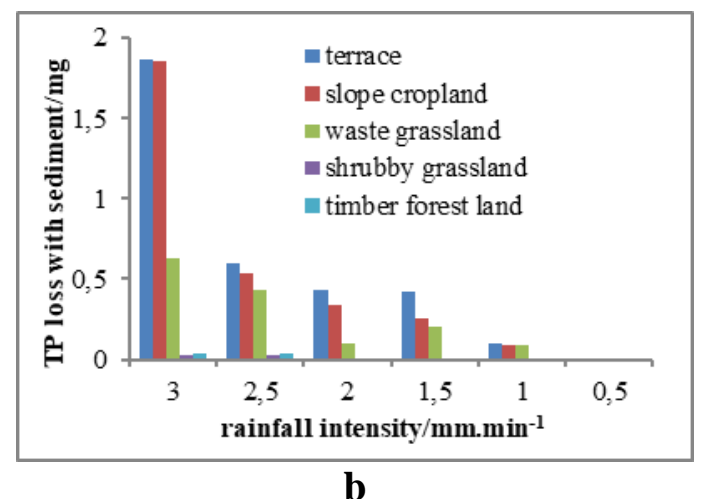

b

Figure 2. The rule of TN drain (a) and TP drain (b) in sediment samples

\section{Nutrients enrichment in sediment drain}

Researches indicated the phenomenon of nutrients enrichment existed in the sediment drain (Guo et al., 2014; Zhang et al., 2015). According to the tested soil, the nutrients enrichment rule in silt load and bed load were shown in Table 2 (no analysis the enrichment of silt load in timber forest and shrubby grassland due to lower amount). Nutrients content of silt load were higher than the one of bed load in Table 2. Nutrients Enrichment rate (NER) means that nutrients content in sediment is divided by the sediment yield, which can characterize the state of nutrients accumulation in sediment. 


$$
\text { - } 455 \text { - }
$$

The soil of arable layer is easy to erode out of human activities and there are more fine grain and compound grain in farmland soil that makes nutrients enrichment more obvious in sediment drain, so the content of TN and TP in silt load is higher than that in bed load.

Table 2. Nutrient enrichment rate in sediment drain

\begin{tabular}{c|c|c|c|c}
\hline \multirow{2}{*}{ Soil types } & \multicolumn{2}{|c|}{ NER of bed load } & \multicolumn{2}{c}{ NER of silt load } \\
\cline { 2 - 5 } & TN & TP & TN & TP \\
\hline Slope cropland & 1.17 & 1.15 & 1.76 & 1.54 \\
Terrace & 1.47 & 1.07 & 2.43 & 1.95 \\
Waste-grassland & 1.08 & 1.27 & 1.23 & 1.57 \\
Shrubby grassland & 1.15 & 1.53 & & \\
Timber forest & 1.11 & 1.19 & & \\
\hline
\end{tabular}

\section{Correlativity of nutrients loss and runoff, sediment}

\section{The relationship between nutrients loss and runoff}

Researches manifested there was an obvious correlativity between surface runoff and non-point source pollution load (Wang et al., 2016, 2017a), and there was a relationship of power exponent between two elements by references ( $\mathrm{Lv}$ et al., 2015; Shi et al., 2016). In this research, the amount of pollutant output was computed by the following formula:

$$
\mathrm{M}=\sum Q_{\mathrm{i}} \times \mathrm{C}_{\mathrm{i}}
$$

In the formula, $M$ is total amount of pollutant output accumulated in each period from the beginning of rainfall; $Q_{i}$ stands for runoff/sediment drain for period i; $\mathrm{C}_{i}$ means concentration of pollutant at period $i$.

According to the formula, there was a significantly positive correlation among the loss of TN, TP and runoff, the fitting equations of which were shown in Table 3. $\mathrm{M}_{\mathrm{TN}}$ expressed total output of TN namely the sum of each period, so was $\mathrm{M}_{\mathrm{TP}}$; $\mathrm{Q}$ represented runoff volume.

Table 3. The fitting equations of nutrients loss and runoff

\begin{tabular}{c|c|c}
\hline Soil types & Fitting equations & Correlation index \\
\hline Timber forest & $\mathrm{M}_{\mathrm{TN}}=0.2058 \mathrm{Q}^{1.2016}$ & 0.9949 \\
Shrubby grassland & $\mathrm{M}_{\mathrm{TN}}=0.3793 \mathrm{Q}^{0.9278}$ & 0.9998 \\
Waste-grassland & $\mathrm{M}_{\mathrm{TN}}=0.2233 \mathrm{Q}^{1.1995}$ & 0.9951 \\
Terrace & $\mathrm{M}_{\mathrm{TN}}=0.1592 \mathrm{Q}^{1.2678}$ & 0.9890 \\
Slope cropland & $\mathrm{M}_{\mathrm{TN}}=1.5588 \mathrm{Q}^{0.7217}$ & 0.9895 \\
Timber forest & $\mathrm{M}_{\mathrm{TP}}=0.1135 \mathrm{Q}^{1.0921}$ & 0.9769 \\
Shrubby grassland & $\mathrm{M}_{\mathrm{TP}}=0.0034 \mathrm{Q}^{1.8322}$ & 0.9643 \\
Waste-grassland & $\mathrm{M}_{\mathrm{TP}}=0.0051 \mathrm{Q}^{1.909}$ & 0.9885 \\
Terrace & $\mathrm{M}_{\mathrm{TP}}=0.0032 \mathrm{Q}^{1.2678}$ & 0.9589 \\
Slope cropland & $\mathrm{M}_{\mathrm{TP}}=0.0179 \mathrm{Q}^{0.9172}$ & 0.9587 \\
\hline
\end{tabular}




$$
-456-
$$

\section{The relationship between nutrients loss and sediment drain}

The linear regression analysis of nutrients loss and sediment drain was done and the regression equations were shown in Table 4. Q was sediment drain and $\mathrm{M}$ meant nutrients loss in the table, $\mathrm{M}_{\mathrm{TN}}$ expressed the loss of $\mathrm{TN}$ and $\mathrm{M}_{\mathrm{TP}}$ represented the drain of TP.

Table 4. The regression equations of nutrients loss and soil erosion

\begin{tabular}{c|c|c}
\hline Soil types & Regression equations & Correlation index \\
\hline Timber forest & $\mathrm{M}_{\mathrm{TN}}=0.2065 \mathrm{Q}+0.0124$ & 0.9991 \\
Shrubby grassland & $\mathrm{M}_{\mathrm{TN}}=0.2135 \mathrm{Q}-0.0003$ & 0.9934 \\
Waste-grassland & $\mathrm{M}_{\mathrm{TN}}=0.3283 \mathrm{Q}-0.0271$ & 0.9907 \\
Terrace & $\mathrm{M}_{\mathrm{TN}}=0.2033 \mathrm{Q}-0.0002$ & 0.9979 \\
Slope cropland & $\mathrm{M}_{\mathrm{TN}}=0.2219 \mathrm{Q}-0.0007$ & 0.9914 \\
Timber forest & $\mathrm{M}_{\mathrm{TP}}=0.5525 \mathrm{Q}+0.0524$ & 0.9955 \\
Shrubby grassland & $\mathrm{M}_{\mathrm{TP}}=0.7652 \mathrm{Q}+0.0024$ & 0.9798 \\
Waste-grassland & $\mathrm{M}_{\mathrm{TP}}=0.3017 \mathrm{Q}+0.0424$ & 0.9628 \\
Terrace & $\mathrm{M}_{\mathrm{TP}}=0.9601 \mathrm{Q}+0.0002$ & 0.9991 \\
Slope cropland & $\mathrm{M}_{\mathrm{TP}}=0.554 \mathrm{Q}+0.0038$ & 0.9765 \\
\hline
\end{tabular}

\section{Comparison on nutrients content of runoff and sediment erosion in topsoil}

There are two main forms for nutrients drain, one is pollutants which are attracted by soil particles eroding with the soil particles drained, the other is pollutants that are easy soluble in water by leaching into the runoff. In this paper, the nutrients loss ways for slope cropland were shown in Figure $3 a, b$.

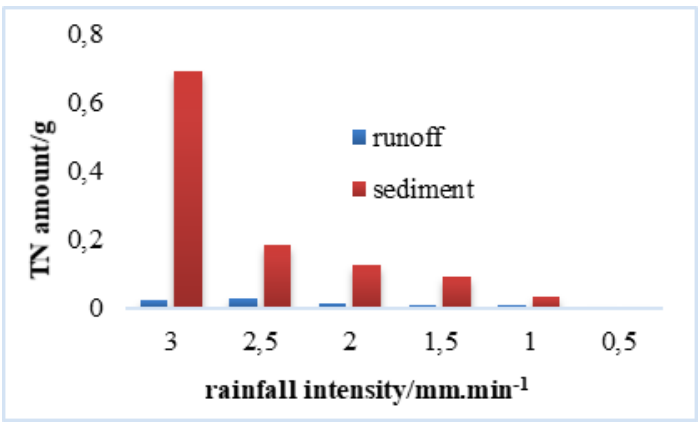

$\mathbf{a}$

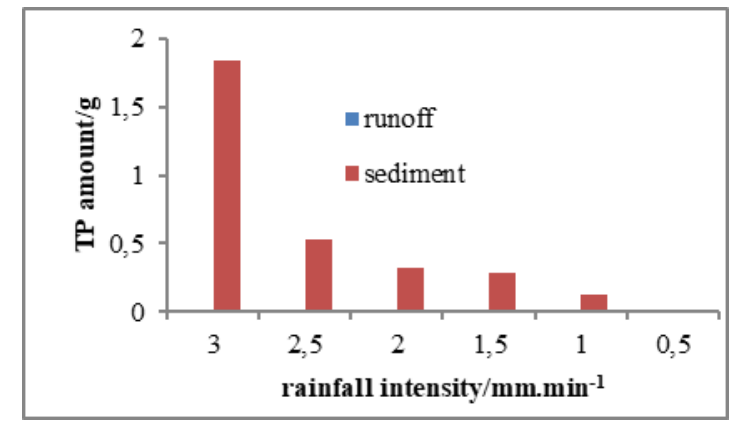

b

Figure 3. TN (a) and TP (b) amount in runoff and sediment drain in slope cropland

By Figure $3 a, b$, the proportion of nutrients loss with runoff was not large in total nutrients drain and the majority of nutrients were washed away by sediment in slope cropland (namely farmland). TN loss with sediment was far more than that with runoff, the times of them changed between 6.7 with 25.55 because of different rainfall intensity; the times of TP loss with sediment floated from 53.97 to 109.92 compared with that with runoff, which showed nutrients eroded was adsorbed by the fine grain of 
soil and carried by sediment drain that was the main way of agricultural non-point source pollution.

Through Figure $4 a, b$, in the soil of timber forest namely woodland, loss of TN with runoff far outweighed that with sediment while the loss of TP mainly disappeared with sediment drain. On same rainfall intensity, TN loss with sediment was 0.13 0.22 times of that with runoff and TP loss with sediment was 1.84 6.6 times of that with runoff.

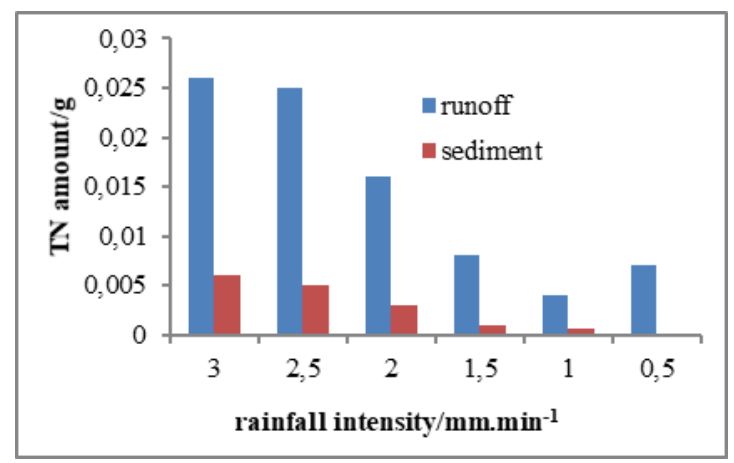

$\mathbf{a}$

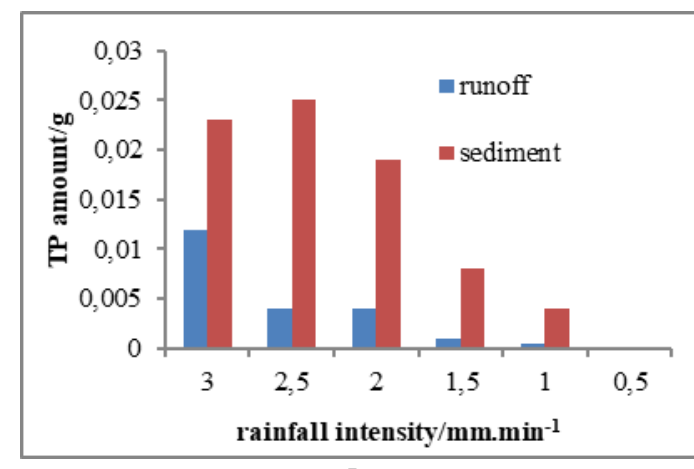

b

Figure 4. $T N(a)$ and $T P(b)$ amount in runoff and sediment erosion in timber forest

From Figures 3 and 4, the nutrients loss with sediment was higher than that with runoff in farmland soil, which was consistent with the results of Wang et al. (2016) and Yao et al. (2013). The loss of TN with sediment was less than that with runoff in forest land and the nutrients loss in woodland was less than the one in farmland. Reason could be from two sides, for one thing, the flow yield was less because of good infiltration in woodland to reduce soil erosion; for another, soil particles eroded were larger carrying little nutrients, which made less nutrients lose with sediment. In addition, gradient influence had not been considered in the experiments, and usually, nutrients loss gradually increased with the increase of slope.

\section{The statistical analysis of land use and rainfall intensity on nutrient loss}

\section{Variance analysis of land use and rainfall intensity on the nutrient loss in runoff}

Two-factor variance analyses were done by SAS software to study the influence of land use and rainfall intensity on the nutrient loss in runoff, whose results were shown in Table 5.

Table 5. Variance analysis of land use and rainfall intensity on TN and TP loss in runoff

\begin{tabular}{c|c|c|c|c|c|c}
\hline Indexes & Source & DF & SS & MS & F value & Pr. $>$ F \\
\hline \multirow{4}{*}{ TN } & Land use types & 4 & 17.893347 & 4.473337 & 12.51 & $<0.0001$ \\
& Rainfall intensity & 5 & 2430.826067 & 486.165213 & 1360.11 & $<0.0001$ \\
& Error & 20 & 7.148933 & 0.357447 & & \\
& Total & 29 & 2455.868347 & & & \\
\hline \multirow{4}{*}{ TP } & Land use types & 4 & 13.2784867 & 3.3196217 & 3.03 & 0.0419 \\
& Rainfall intensity & 5 & 633.9812567 & 126.7962513 & 115.63 & $<0.0001$ \\
& Error & 20 & 21.9315933 & 1.0965797 & & \\
& Total & 29 & 669.31913367 & & & \\
\hline
\end{tabular}


From Table 5, both land use types and rainfall intensity had significant effects on TN loss in runoff whose significant level was Pr. $<0.0001$. The influence of land use types on TP was slightly significant at 0.05 of confidence level while it was not significant on confidence level of 0.01 ; there was a significant effect for rainfall intensity on TP loss in runoff whose significant level was Pr. $<0.0001$.

\section{Variance analysis of land use and rainfall intensity on the nutrient loss in sediment}

The variance analysis results of land use and rainfall intensity on TN and TP in sediment were shown in Table 6.

Table 6. Variance analysis of land use and rainfall intensity on TN and TP loss in sediment

\begin{tabular}{c|c|c|c|c|c|c}
\hline Indexes & Source & DF & SS & MS & F value & Pr. > F \\
\hline \multirow{4}{*}{ TN } & Land use types & 4 & 0.25713567 & 0.06428392 & 3.62 & 0.0225 \\
& Rainfall intensity & 5 & 0.53330200 & 0.10666040 & 6.0 & 0.0015 \\
& Error & 20 & 0.35557633 & 0.01777882 & & \\
& Total & 29 & 1.14601400 & & & \\
\hline \multirow{4}{*}{ TP } & Land use types & 4 & 1.69064913 & 0.42266228 & 3.6 & 0.0229 \\
& Rainfall intensity & 5 & 2.58242240 & 0.51648448 & 4.4 & 0.0073 \\
& Error & 20 & 2.34732527 & 0.11736626 & & \\
& Total & 29 & 6.62039680 & & & \\
\hline
\end{tabular}

Based on Table 6, land use types had some influence on TN and TP in sediment at 0.05 of confidence level while it had no effect on confidence level of 0.01 ; rainfall intensity made a significant effect on $\mathrm{TN}$ and $\mathrm{TP}$ in sediment whose significant level was respectively 0.0015 and 0.0073 .

\section{Discussion}

The physical properties of soil are the internal factors leading to soil erosion, the degree of soil erosion is usually related to the physical properties of soil itself under certain external forces (Kaya et al., 2016). The above research showed that the soil of timber forest and shrubby grassland could absorb nutrients and reduce soil erosion out of better soil structure; under the same rainfall conditions, the loss of terraced soil in runoff and sediment were all lower than sloping farmland while the concentration of TN and TP were higher than that of other soil, which fully indicated that terrace could store and collect nutrients and achieve on-site infiltration of rainwater.

It is easy to produce soil erosion because of complex topography and abundant rainfall in study area, moreover, Danjiangkou reservoir is water source area of south-tonorth water transfer project, its water quality is related to the success of the project. Therefore, it is necessary to adjust the land use structure in the region that restoring steep slope land to forest and grass and changing gentle slope land to terrace, so as to improve crop yield and control soil erosion, non-point agricultural pollution and ensure the water quality safety of the reservoir. 


\section{Conclusions}

It was studied that the nutrients loss rule of five types of soil in southwest mountains in Henan Province under six kinds of rainfall intensity by artificial rainfall tests and the results were that:

(1) The loss of nutrients, runoff and sediment drain were larger with rainfall intensity increasing in same type soil. On same rainfall intensity, nutrients loss of farmland soil was larger than that in woodland and grassland, the nutrients content in terrace was higher than that in other soil. (2) Due to nutrients enrichment in sediment drain, the nutrients content in silt load was higher than that in bed load. By regression analysis, there was the relationship of power index in nutrients loss and runoff while it was a linear correlation between sediment erosion and nutrients loss. (3) The nutrients in farmland mainly went away with sediment erosion while in forest land, the TN loss with sediment was less than that with runoff and the loss of TP was on the contrary. (4) At 0.01 of confidence degree, there was a significant effect for rainfall intensity on nutrients loss in runoff and sediment; Land use types made a significant influence on the TN loss in runoff but no effect on the TP drain while it had no prominent effect on nutrients loss in sediment.

Above research shows that the land use structure is unreasonable in the region and it is urgent to adjust with returning to forest and grass in steep slope land and turning hillsides to terrace in gentle slope, which can not only improve crop yield, but also control soil erosion and non-point agricultural pollution and ensure water quality safety of the reservoir.

Acknowledgements. The paper was written by the items "Study on Agricultural Non-point Source Pollution in the Water Source Area of Danjiangkou Reservoir Based on Fractal Theory and its Prevention Measures (GG201412)" and funded by the subject "the Risk Assessment of Water Quality and Security System Research for Reservoir Water Source Area in Henan Province (GG201612)", which applied the detailed data and funding that should be firstly appreciated. And the staff of institute of soil and water conservation CAS paying more efforts to the experiments of artificial simulated rainfall ought to be respected.

\section{REFERENCES}

[1] Beibei, Y., Kai, H., Dezhi, S. et al. (2017): Mapping the scientific research on non-point source pollution: a bibliometric analysis. - Environmental Science and Pollution Research 24: 4352-4366.

[2] Guo, X., Song, F., Gao, Y. et al. (2014): Characteristics of lost sediment and its nutrient enriched effect on three types soil slope under simulated rainfall. - Journal of Soil and Water Conservation 28: 23-28.

[3] He, T., Qin, F., Su, T. et al. (2014): Effect of different cultivation methods on nitrogen and phosphorus losses along with runoff. - Research of Soil and Water Conservation 21: 95-103.

[4] Huan, J. (2012): Water Quality-Determination of Total Nitrogen-Alkaline Potassium Persulfate Digestion UV Spectrophotometric Method. - China Environmental Science Press, Beijing.

[5] Kaya, A., Alemdag, S., Dag, S. et al. (2016): Stability assessment of high-steep cut slope debris on a landslide (Gumushane, NE, Turkey). - Bulletin of Engineering Geology and the Environment 75: 89-99. 
[6] Li, Y., Chen, Y. (2015): The path of the prevention legislation in agriculture non-point source water pollution in China under the background of transformation. - Jiangsu Agricultural Sciences 43: 441-443.

[7] Li, Y., Hu, Y. (2013): Strategy of controlling agricultural non-point pollution in Minjiang River basin. - Journal of Fujian Agricultural and Forestry University (Philosophy and Social Sciences) 16: 5-8.

[8] Li, Z. (2013): Review of the current situation and control countermeasures in agricultural non-point source pollution control in China. - Agricultural Research in the Arid Areas 31: 207-212.

[9] Lv, Y., Peng, X., Gao, L. et al. (2015): Characteristics of nitrogen and phosphorus losses through surface runoff on sloping land, red soil hilly region. - Soils 47: 297-304.

[10] Mureithi, S. M., Verdoodt, A., Gachene, C. K. et al. (2014): Impact of enclosure management on soil properties and microbial biomass in a restored semi-arid rangeland, Kenya. - Journal of Arid Land 72: 561-570.

[11] Shen, Y., Li, L. (2013): Modification of ammonium molybdate spectrophotometric method for measurement of dissolved phosphorus. - Experimental Technology and Management 30: 56-59.

[12] Shi, Y., Huang, J., Ni, X. et al. (2016): Effects of fertilization on surface runoff loss of nitrogen and phosphorus from mulberry in the northern Zhejiang Plain, China. - AgroEnvironment and Development 33: 518-524.

[13] Tang, J., Liu, C., Yang, W. et al. (2012): Spatial distribution of non-point source pollution in Dahuofang Reservoir catchment based on swat model. - Scientia Geographica Sinica 32: 1247-1253.

[14] Wang, G., Li, Z., Tian, Y. et al. (2016): Effects of rainfall intensity and land use mode on loss of TN and TP in southwest hilly area of Henan Province. - Yangtze River 47: 18-22.

[15] Wang, G., Li, Z., Qu, J. et al. (2017a): Features of soil nutrients loss under different land use in southwest mountainous areas of Henan Province. - Bulletin of Soil and Water Conservation 37: 83-88.

[16] Wang, G., Li, Z., Tian, Y. et al. (2017b): Effects of rainfall intensity and land use on flow volume and sediment yield in Southwest Coteau of Henan Province. - Engineering Journal of Wuhan University 50: 182-186.

[17] Wang, G., Li, Z., Zuo, Q. et al. (2017c): T estimation of agricultural non-point source pollutant loss in catchment areas of Danjiangkou Reservoir. - Research of Environmental Science 30: 415-422.

[18] Wang, Q., Yang, T., Liu, Y. et al. (2016): Review of soil nutrient transport in runoff and its controlling measures. - Journal of Agricultural Machinery 47: 67-82.

[19] Wang, Z., Yang, Y., Ren, R. et al. (2016): Method comparison between ICP-AES and ammonium Molybdate spectrophotometry in determination of total phosphorus in industrial wastewater. - The Administration and Technique of Environmental Monitoring 28: 58-61.

[20] Wu, D., Huang, Z., Xiao, W. et al. (2015): Control of soil nutrient loss of typical reforestation patterns along the three gorges reservoir area. - Environmental Science 36: 3825-3831.

[21] Xi, Y., Tian, W., Li, Y. et al. (2014): Nitrogen and phosphorus runoff losses and loss coefficients in rice-wheat rotation system in Taihu Lake basin. - Jiangsu Journal of Agricultural Sciences 30: 534-540.

[22] Yang, L., Feng, Y., Shi, W. et al. (2013): Review of the advances and development trends in agricultural non-point source pollution control in China. - Chinese Journal of EcoAgriculture 21: 96-101.

[23] Yao, N., Cheng, Y., Cai, C. (2013): Study on the nitrogen enrichment experiment of purple soil. - Subtropical Soil and Water Conservation 25: 14-18. 


$$
-461 \text { - }
$$

[24] Yu, H., Yang, Z., Xiao, R. et al. (2013): Absorption capacity of nitrogen and phosphorus of aquatic plants and harvest management research. - Acta Prataculturae Sinica 22: 294299.

[25] Zhang, J., Liu, D., Jiang, X. et al. (2015): Research on soil erosion using remote sensing method in Danjiangkou Reservoir - A case study of Shangnan County. - Journal of Agricultural Resources and Environment 32: 162-168.

[26] Zhang, L., Wu, M., Wan, Y. (2018): Study on countermeasures for water quality security of the Danjiangkou Reservoir. - China Water Resources 1: 44-47.

[27] Zhang, Y., Ding, Y., Wang, D. et al. (2015): Effects of slope gradient on yield and particle size distribution of sediment. - Journal of Soil and Water Conservation 29: 2529.

[28] Zhou, H. (2014): The influence of railway construction on ecological service function and soil erosion problem. - Technology of Road and Bridge 14: 204-205. 